\title{
The Efficacy of Different Inflammatory Markers for the Prognosis of Patients with Malignant Tumors
}

\author{
Kaiwen Zheng $\mathbb{D}^{*}$ \\ Xiangliang Liu* \\ Wei Ji* \\ Jin Lu \\ Jiuwei Cui \\ Wei Li
}

Cancer Center, the First Hospital of JiLin University, Changchun, Jilin, People's

Republic of China

*These authors contributed equally to this work
Correspondence: Jiuwei Cui; Wei Li Email cuijw@jlu.edu.cn; liwei66@jlu.edu.cn
Background: Inflammation is considered essential in cancer progression, as it affects the nutritional status and prognosis of patients. In this study, we aim to analyze the efficacy of various inflammatory markers in predicting prognosis in cancer patients.

Methods: Patients with malignant tumor were included as primary and validation cohort. Basic clinical information, anthropometric indicators, body composition analysis, and serological indicators were recorded. After proposing the optimal thresholds by time-dependent receiver operating characteristic (ROC), univariate and multivariate Cox regression analyses were performed to analyze the association between inflammatory markers and overall survival (OS). A nomogram was established to develop a scored-inflammatory marker system. Eight inflammatory models based on combinations of inflammatory markers were assessed. Cox regression analysis was used to analyze the relationship of each inflammatory model and mortality of participants. Then, subanalysis of specific tumor types was conducted by Cox regression. Logistic regression models were used to analyze the relationship between different inflammatory models and malnutrition.

Results: Univariate and multivariate Cox regression analyses indicated that pack-years of cigarette smoking, C-reactive protein (CRP), and systemic immune-inflammation index (SII) were related to the OS of cancer patients. A nomogram was constructed to develop a scoredinflammatory marker system. Among the eight inflammatory models, patients in model A had worst prognosis compared with patients in other models. Subanalysis next showed lung cancer, breast cancer and digestive system neoplasms patients in model A suffered the worst prognosis. Logistic regression indicated that model A was also with predictive value for malnutrition.

Conclusion: A scored-inflammatory marker system was established to predict the OS of cancer patients. The inflammatory models established in this study can be used to predict prognosis, as well as cancer-related malnutrition. Inflammatory model A suffered the worst OS and was with the predictive efficacy for malnutrition.

Keywords: cancer, inflammatory markers, nutritional status, overall survival

\section{Background}

For the past few years, the incidence of cancer has seen a steady increase. According to data from GLOBOCAN, ${ }^{1}$ an estimated 19.3 million new cancer cases were diagnosed and approximately 10 million cancer deaths recorded worldwide in 2020 . The emergence of cancer into the mainstream of chronic disease is related to the transition of epidemiology in developing countries to a certain extent. ${ }^{2,3}$ In the vast majority of countries, cancer already ranks as the leading cause of death in individuals younger 
than 70 years, and this tendency will remain in the coming decades. $^{3}$ Although great advances have been achieved in cancer therapy, systemic comprehensive treatment is also deemed effective and important especially in advanced cancer, ${ }^{4}$ which encourages clinicians to look for biomarkers that are highly predictive of the outcome of cancer patients.

The association between cancer and inflammation has been previously described. As early as the nineteenth century, German pathologist Rudolf Virchow has already considered chronic inflammation as a factor in the origin of cancer. ${ }^{5}$ Over the years, the connection between cancer and inflammation has changed both treatment and management strategies. ${ }^{6}$ Inflammation is an integral component at all three stages of tumor initiation, progression and metastasis through processes that involve genotoxicity, aberrant tissue repair, proliferative responses, and immune surveillance. ${ }^{7,8}$ Cytokines with proinflammatory and inflammatory properties can stimulate or inhibit tumor growth and progression. ${ }^{9}$ Pro-inflammatory cytokines that involve in carcinogenesis include interleukin-1 (IL-1), IL-6 and tumor necrosis factor alpha (TNF- $\alpha$ ). Besides, macrophage migration inhibitory factor (MIF) and nuclear

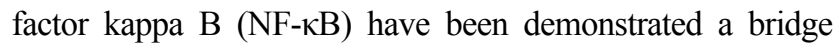
between inflammation and cancer. MIF has unique biological activities including regulating p53 gene, angiogenesis, cell cycle, and senescence. ${ }^{10} \mathrm{NF}-\kappa \mathrm{B}$ inhibits apoptosis, promotes cell cycle progression and angiogenesis through gene regulation, such as those genes encoding BCL-XL (B-cell lymphoma XL), BFL1 (a BCL-2-related protein) and GADD45 $\beta$ (growth arrest and DNA-damage-inducible $45 \beta$ ). ${ }^{11,12}$ From clinical perspectives, studies have reported the role of systemic inflammatory markers in cancer management and prognosis, including the most common inflammatory parameter, C-reactive protein (CRP) ${ }^{13,14}$ in terms of treatment efficacy and survival, and certain circulating immune cells, such as monocytes and the neutrophil-to-lymphocyte ratio (NLR) as cancer treatment biomarkers. ${ }^{15,16}$ In addition, some researchers have proposed the Glasgow Prognostic Score and systemic immune-inflammation index (SII) for their ability in reflecting the degree of inflammation and the immune status of patients. $^{17,18}$

Nutritional status is also an important part in the process of cancer management. The guidelines clearly state that cancer patients should pay attention to their nutritional status, which is often ignored in current clinical work-up. ${ }^{19}$ Inflammation plays an important role in the pathogenesis of malnutrition. Pro-inflammatory cytokines, including IL-1 $\beta$, IL-6, and TNF$\alpha$, may participant in malnutrition development during the course of chronic diseases. Earlier studies have found that changes in serum levels of pro-inflammatory factors are potential predictors of malnutrition and the effect of oral nutritional supplements is pronounced in patients who lack signs of persistent inflammatory activity. ${ }^{20}$ Inflammatory mediators also lead to changes in protein and liver metabolism, result in the negative balance state of body's energy metabolism. ${ }^{21}$ Besides, inflammation causes increased muscle catabolism, which is named sarcopenia, and is related to deteriorated nutritional status and clinical outcomes. ${ }^{22}$

Inflammation and nutritional status, which are interrelated in cancer patients, coordinately affect cancer development..$^{23-25}$ Due to their reproducibility, convenience, and objectivity, clinical indicators are very promising in cancer management. Although previous studies have provided a number of predictive indicators for clinical practice, the inflammatory biomarker which obtains the strongest correlation with the patient's prognostic outcome is still not validated. In addition, cancer treatment is a dynamically changing process managed by clinical decision-makers. Whether one certain indicator can comprehensively reflect the overall situation of patients is still a question that deserves in-depth exploration. In this study, the proper thresholds of multi inflammatory markers were proposed according to prognostic statistics firstly. Then, a scored-inflammatory marker system for predicting overall survival (OS) in cancer patients was constructed and validated. An optimal inflammatory model correlated with prognosis was selected. In addition, the efficacy of inflammatory models in predicting malnutrition was examined and reported.

\section{Method}

\section{Study Participants}

This study is a retrospective study. In primary cohort, data are derived from Cancer Center of the First Affiliated Hospital of Jilin University from January 2012 to December 2020. Patients with malignant tumors who met the criteria were included in this study, while those whose records lacked critical information were excluded. The inclusion criteria were as follows: (1) cancer confirmed by pathology with an Eastern Cooperative Oncology Group performance status of 0 or 1 ; (2) no anti-tumor therapy or related therapy before assessment; and (3) no metabolic disease or autoimmune disease. Meanwhile, the exclusion criteria were as follows: (1) patients with other types of tumors and (2) patients who died within 30 days of admission. Participants were followed from the initial admission until they died or until the end of December 2020. 
In validation cohort, data are derived from the Investigation on Nutrition Status and its Clinical Outcome of Common Cancers (INSCOC), which is a nation-wide cross-sectional survey on the correlation between nutritional status and clinical outcome in patients with malignant tumors in China. Cancer patients with the same inclusion and exclusion criteria were enrolled as validation cohort and followed up from January 2012 to December 2020.

All pathological stagings were defined according to the 8th edition of the American Joint Committee on Cancer (AJCC) TNM staging system. This study was approved by the medical ethical review committee of the registration hospital and was performed in accordance with the Declaration of Helsinki.

\section{Data Collection}

The main outcome was OS of participants in primary cohort and validation cohort, defined as the time from the initial admission until they died, or until the end of the follow-up date, December 2020. All participants underwent anthropometric measurements and laboratory biochemical testing within 24 hours of admission. For each patient, the following data were collected: gender, age at first diagnosis, tumor type, tumor stage, weight change in the past 6 months after diagnosis and smoking history. Hematological indicators, including albumin (Alb), CRP, NLR and platelet-to-lymphocyte ratio, were also recorded. The Glasgow Prognostic Score ${ }^{17}$ was calculated based on the Alb and CRP levels, as detailed in the Appendix, Table 1. SII was calculated using the formula platelet $\times$ neutrophil/lymphocyte, according to the cell counts in the peripheral blood. ${ }^{18}$ Pack-years of cigarette smoking was calculated by packs of cigarette per day $x$ smoking years.

Height and weight were measured to an accuracy of $1 \mathrm{~cm}$ and $0.1 \mathrm{~kg}$, respectively. Body mass index (BMI) was calculated according to the formula weight $(\mathrm{kg}) /$ height $^{2}(\mathrm{~m})^{2}$. Circumference of the mid-upper arm (MAC) of the non-dominant side and calf circumference (CC) of the left leg were measured to the nearest $0.5 \mathrm{~cm}$ using a non-elastic tape when patients were in the standing position. Skinfold thickness (TSF) in the same area was measured accurately to $1 \mathrm{~mm}$ using vernier calipers. Mid-upper arm muscle circumference $(\mathrm{cm})$ was calculated by MAC $(\mathrm{cm})-\pi \times[T S F(\mathrm{~mm}) / 10]$. Patients were seated with $90^{\circ}$ elbow flexion. The grip strength (HGS) of the non-dominant hand was measured to the nearest $1 \mathrm{~kg}$ at least twice using a Jamar dynamometer, and the maximum reading was recorded. HGS was corrected according to weight, and then $\mathrm{HGS} / \mathrm{W}$ was calculated by HGS $(\mathrm{kg}) /$ weight $(\mathrm{kg})$.

\section{Body Composition Analysis by Bioelectrical Impedance Analysis (BIA)}

Patients underwent BIA within 24 hours of admission. Before the measurement, patients voided their bladders, fasted for at least 2 hours, and wore a uniform hospital gown; they also avoided physical activity and remained quiet. The multi-frequency bioelectrical impedance body composition analyzer InbodyS10 (Biospace $\mathrm{Co}^{\circledR}$ ) was used for these measurements. During testing, the patients stood on the instrument with the limbs in contact with 8-point contact electrodes. Relevant data, including fat-free mass (FFM, $\mathrm{kg}$ ), body fat mass (BFM, kg), extracellular water (ECW), and total body water, were recorded. The fat-free body mass index (FFMI) was calculated by FFM (kg)/height ${ }^{2}(\mathrm{~m})^{2}$.

\section{Nutritional Status}

Nutritional status was assessed according to the Global Leadership Initiative on Malnutrition (GLIM) guidelines. ${ }^{26}$ The criteria for malnutrition diagnosis were as follows: (1) phenotypic criteria: a. non-volitional weight loss; b. low BMI; c. reduced muscle mass; (2) etiologic criteria: a. reduced food intake or assimilation; b. disease burden/inflammation. For a diagnosis of malnutrition, at least one phenotypic criterion and one etiologic criterion are met. All participants in this study were diagnosed with cancer, thus they all met the disease burden. According to the suggested phenotypic metrics, malnutrition was graded as malnutrition stage I (moderate malnutrition) or malnutrition stage II (severe malnutrition). The selected thresholds for the diagnosis of malnutrition and severity grading are shown in the Appendix, Table 2.

\section{Statistical Analysis}

SPSS 26.0 statistical software and R Project for Statistical Computing (version 4.0.5) were used for data analyses. Continuous variables were expressed as the mean \pm standard deviation, and categorical variables were presented as counts (\%). Time-dependent ROC curves were used to determine the optimal cut-off values of the inflammatory markers. Univariate and multivariate Cox regression analyses were performed to determine the association between inflammatory markers and OS. A nomogram was generated to develop the scored-inflammatory marker system with statistically significant variables of multivariate Cox 
regression. C-index, ROC curve and calibration curve analyses were performed to validate the predictive accuracy of the scored-inflammatory marker system, both in primary cohort and validation cohort. Statistically significant inflammatory markers were then combined based on the Cox regression results to form eight inflammatory models. Kaplan-Meier curve and univariate Cox regression were used to compare the OS of patients among eight inflammatory models, and subanalysis of specific tumor type was conducted by Cox regression. Then, logistic regression models were used to analyze the relationship between the inflammatory model and malnutrition.

\section{Results}

\section{Baseline Characteristic of the Study Population}

In total, 2415 patients qualified and were included in this study as primary cohort, and of these, 995 were males (41.2\%), while 1420 were females (58.8\%). Lung cancer patients comprised the majority of study subjects ( 873 patients, 36.1\%), followed by breast cancer patients (698 patients, $28.9 \%$ ). In addition, 678 patients had digestive system neoplasms, including esophageal cancer, gastric cancer, and colorectal cancer. The remaining 166 patients had gynecological oncology, including ovarian cancer, endometrial cancer, and cervical cancer. The patients' nutritional status was retrospectively assessed using the GLIM criteria. ${ }^{26}$ Overall, $66.0 \%$ of patients were diagnosed with malnutrition, among whom $49.2 \%$ had stage I malnutrition and $16.8 \%$ had stage II malnutrition (see Table 1 for detailed clinical information). In addition, another group of consecutive cancer patients $(n=2014)$ with the same inclusion and exclusion criteria were enrolled, and this group of patients was used to form the validation cohort of this study.

\section{Derivation of Inflammatory Markers Related to Cancer Prognosis}

The inflammatory markers Alb, NLR, CRP, pack-years of cigarette smoking, Glasgow Prognostic Scores, and SII were analyzed. Among the inflammatory markers, the OS of patients was used as the observation endpoint, and the optimal cut-off value was selected using the timedependent ROC curve in $\mathrm{R}$ Project for Statistical Computing. After analysis, the optimal cut-off values were determined: $5 \mathrm{mg} / \mathrm{L}$ for CRP (AUC = 0.697); 2.45
Table I Detailed Baseline Characteristics of the Study Population in the Primary Cohort $(n=2415)$

\begin{tabular}{|c|c|}
\hline Characteristics & n (\%)/meants.d. \\
\hline \multicolumn{2}{|l|}{ Gender } \\
\hline Male & 995 (4I.2\%) \\
\hline Female & $1420(58.8 \%)$ \\
\hline \multicolumn{2}{|l|}{ Age } \\
\hline$<65$ & 1807 (74.8\%) \\
\hline$\geq 65$ & $608(25.2 \%)$ \\
\hline \multicolumn{2}{|l|}{ Smoking History } \\
\hline No & 1455 (60.2\%) \\
\hline Yes/ever & $960(39.8 \%)$ \\
\hline \multicolumn{2}{|l|}{ Tumor type } \\
\hline Lung cancer & $873(36.1 \%)$ \\
\hline Breast cancer & 698 (28.9\%) \\
\hline Digestive system neoplasms & $678(28.1 \%)$ \\
\hline Gynecologic oncology & 166 (6.9\%) \\
\hline \multicolumn{2}{|l|}{ Tumor stage } \\
\hline I & 475 (19.7\%) \\
\hline II & $626(25.9 \%)$ \\
\hline III & 756 (31.3\%) \\
\hline IV & $558(23.1 \%)$ \\
\hline BMI $\left(\mathrm{kg} / \mathrm{m}^{2}\right)$ & $23.66 \pm 5.18$ \\
\hline $\operatorname{MAC}(\mathrm{cm})$ & $27.05 \pm 4.02$ \\
\hline HGS/W & $0.38 \pm 0.14$ \\
\hline $\mathrm{CC}(\mathrm{cm})$ & $34.17 \pm 4.09$ \\
\hline FFM (kg) & $45.50 \pm 11.05$ \\
\hline ASM (kg) & $42.75 \pm 10.71$ \\
\hline ECW/TBW & $0.3874 \pm 0.0190$ \\
\hline Alb (g/L) & $39.42 \pm 6.57$ \\
\hline CRP (mg/L) & $16.02 \pm 31.02$ \\
\hline NLR & $3.60 \pm 9.47$ \\
\hline SII & $863.82 \pm 2217.64$ \\
\hline \multicolumn{2}{|l|}{ Glasgow prognostic score } \\
\hline 0 & $18(0.7 \%)$ \\
\hline 1 & 1926 (79.8\%) \\
\hline 2 & 455 (18.8\%) \\
\hline \multicolumn{2}{|l|}{ Nutritional status } \\
\hline Normally nourished & $820(34.0 \%)$ \\
\hline Malnutrition stage I & $1189(49.2 \%)$ \\
\hline Malnutrition stage II & $406(16.8 \%)$ \\
\hline
\end{tabular}

Notes: Continuous variables presented as mean \pm s.d. and categorical variables are presented as counts (\%).

Abbreviations: Alb, Albumin; CRP, C-reactive protein; NLR, neutrophil to lymphocyte ratio; SII, systemic immune-inflammation index; BMI, body mass index; MAC, circumference of the mid-upper arm; HGS/W, the grip strength (HGS) of the non-dominant hand calculated by weight; CC, calf circumference of the left leg; FFM, fat free mass; ASM, appendicular skeletal muscle mass; ECW, extracellular water; TBW, total body water. 
for NLR (AUC = 0.629); 940 for SII (AUC $=0.549) ; 8$ packs $\times$ years for pack-years of cigarette smoking (AUC $=$ 0.669); $35 \mathrm{~g} / \mathrm{L}$ for Alb (AUC = 0.639).

With OS as the observation endpoint, the results of the univariate Cox regression model revealed that the following 10 factors were related to OS: gender, age, tumor type, tumor stage, pack-years of cigarette smoking, Alb, CRP, NLR, SII, and nutritional status. The multivariate Cox regression model then showed that among all the included inflammatory markers, only pack-years of cigarette smoking, CRP, and SII were found to be risk factors related to the prognosis of patients with malignant tumors $(\mathrm{HR}=$ 1.455, 95\% CI of HR 1.166-1.815, $\mathrm{P}=0.001$; $\mathrm{HR}=1.675$, 95\% CI of HR 1.344-2.087, P < 0.001; HR $=1.395,95 \%$ CI of HR 1.064-1.829, P =0.016, see Table 2 for more details). Additionally, tumor stage and tumor type were also related to the OS of cancer patients according to the multivariate Cox regression model. While nutritional status significantly affected prognosis in the univariate Cox regression model, it was not statistically significant in the multivariate Cox regression model.

\section{Development and Validation of a Nomogram for Prognosis-Related Inflammatory Markers}

A nomogram was constructed according to tumor type, tumor stage, pack-years of cigarette smoking, CRP, and SII to develop a scored-inflammatory marker system (Figure 1). Each subtype within these variables was assigned a score based on a point scale. Each variable site was located on the axis, and then a line is drawn straight upward to the Points axis to determine how many points the patient receives from the variables. A scored-inflammatory marker system to determine the estimated probability of survival at each time point was easily obtained by adding the total score and locating it on the total point scale. The C-index of this scoredinflammatory marker system for OS prediction was 0.771 (95\% CI: 0.762 to 0.781 ). Furthermore, the model yielded an AUC of $0.825,0.763$ and 0.682 for prediction of mortality at 1-, 3-, and 5-year (Figure 2A-C). The calibration curves revealed high agreement between predicted probabilities and actual observed survival in 1-, 3- and 5-year (Figure 3A-C).

In the validation cohort, the nomogram had a $\mathrm{C}$-index of 0.680 (95\% CI: 0.674 to 0.686 ) for predicting OS in patients with cancer. The nomogram accurately predicted the overall survival probability, and the 1-, 3- and 5-year AUC values were $0.828,0.830$ and 0.675 , respectively (Figure 4A-C). Finally, the calibration curves showed that the predicted survival probabilities closely corresponded to the actual survival probabilities (Figure $5 \mathrm{~A}-\mathrm{C}$ ).

\section{Correlation Between Each Inflammatory Model and Mortality}

The results of the multivariate Cox regression model above showed that pack-years of cigarette smoking, CRP, and SII were prognostic markers of inflammation. According to the optimal cut-off value of each marker, patients were divided into the high value group and the low value group. The following eight inflammatory models were formed after combining pack-years of cigarette smoking, CRP, and SII, which are shown in Table 3.

The Kaplan-Meier curve and Cox regression model indicated that cancer patients in model $\mathrm{A}$ had a significant higher increased risk of mortality compared with those in other models (HR 6.228, 95\% CI of HR 4.744 8.175, $\mathrm{P}<0.001$, see Table 4 and Figure 6 for more details). Further analysis of the relationship among inflammatory models and specific tumor types is summarized in Table 4, results of which indicated that lung cancer, breast cancer and digestive system neoplasms patients in model A suffered worst prognosis, with a relevant higher HR (HR 3.442, $\mathrm{P}<0.001$, for lung cancer; HR 18.506, $\mathrm{P}<$ 0.001 , for breast cancer; HR 2.492, <0.001, for digestive system neoplasms). Gynecologic oncology patients in model $\mathrm{D}$ were at the highest risk of mortality (HR 46.451, $\mathrm{P}=0.001$, see Table 4 for details).

\section{Correlation Between the Inflammatory Model $A$ and Nutritional Status}

Whether the malnutrition risk of inflammatory model A remains to be a question. Binary logistic regression was used to analyze the relationship between the inflammatory model A and malnutrition in cancer patients. The confounders were gender, age, tumor type, tumor stage and nutritional support. The results of the logistic regression model indicated that the risk of malnutrition was significantly higher in patients represented by model A (HR 1.631, 95\% CI of HR 1.054-2.467, P = 0.027) compared with patients without an inflammatory response, and this difference was deemed statistically significant. A subgroup analysis was performed. The multivariate analysis showed confirmed that the inflammatory model 
Table 2 Univariable and Multivariable Cox Regression of Related Factors in Cancer Patients

\begin{tabular}{|c|c|c|c|c|c|c|}
\hline \multirow[t]{2}{*}{ Relevant Factors } & \multicolumn{3}{|c|}{ Univariable Analysis } & \multicolumn{3}{|c|}{ Multivariable Analysis } \\
\hline & HR & $\begin{array}{c}95 \% \mathrm{Cl} \text { of } \\
\mathrm{HR}\end{array}$ & $\mathbf{P}$ & HR & $\begin{array}{c}95 \% \mathrm{Cl} \text { of } \\
\mathrm{HR}\end{array}$ & $\mathbf{P}$ \\
\hline \multicolumn{7}{|l|}{ Gender } \\
\hline Male & Reference & & & & & \\
\hline Female & 0.372 & $0.315 \sim 0.440$ & $<0.001$ & 0.854 & $0.672 \sim 1.084$ & 0.194 \\
\hline \multicolumn{7}{|l|}{ Age } \\
\hline$<65$ & Reference & & & & & \\
\hline$\geq 65$ & 1.490 & I.253 1.77| & $<0.001$ & 0.924 & $0.747 \sim 1.142$ & 0.465 \\
\hline \multicolumn{7}{|l|}{ Tumor stage } \\
\hline 1 & Reference & & & & & \\
\hline II & 1.868 & I.237 2.82। & 0.003 & 1.716 & $0.945 \sim 3.115$ & 0.076 \\
\hline III & 5.160 & $3.560 \sim 7.479$ & $<0.001$ & 3.786 & $2.213 \sim 6.477$ & $<0.001$ \\
\hline IV & 10.877 & $7.529 \sim 15.712$ & $<0.001$ & 7.452 & $4.374 \sim 12.696$ & $<0.001$ \\
\hline \multicolumn{7}{|l|}{ Tumor type } \\
\hline Gynecologic oncology & Reference & & & & & \\
\hline Digestive system neoplasms & 1.506 & $1.039 \sim 2.181$ & 0.030 & 1.099 & $0.632 \sim 1.911$ & 0.738 \\
\hline Lung cancer & 2.561 & $1.791 \sim 3.664$ & $<0.001$ & 1.655 & $0.975 \sim 2.808$ & 0.062 \\
\hline Breast cancer & 0.214 & $0.133 \sim 0.346$ & $<0.001$ & 0.488 & $0.242 \sim 0.985$ & 0.045 \\
\hline \multicolumn{7}{|l|}{ Pack-years of cigarette smoking } \\
\hline$<8$ & Reference & & & & & \\
\hline$\geq 8$ & 2.527 & $2.148 \sim 2.973$ & $<0.001$ & 1.455 & $1.166 \sim 1.815$ & 0.001 \\
\hline \multicolumn{7}{|l|}{ Nutritional support } \\
\hline No & Reference & & & & & \\
\hline Yes & 1.207 & $0.996 \sim 1.463$ & 0.055 & & & \\
\hline \multicolumn{7}{|l|}{ Alb } \\
\hline$\geq 35$ & Reference & & & & & \\
\hline$<35$ & 1.819 & $1.517 \sim 2.183$ & $<0.001$ & 1.010 & $0.788 \sim 1.296$ & 0.935 \\
\hline \multicolumn{7}{|l|}{ CRP } \\
\hline$<5$ & Reference & & & & & \\
\hline$\geq 5$ & 2.625 & $2.155 \sim 3.198$ & $<0.001$ & 1.675 & 1.344 2.087 & $<0.001$ \\
\hline \multicolumn{7}{|l|}{ NLR } \\
\hline$<2.45$ & Reference & & & & & \\
\hline$\geq 2.45$ & 2.006 & I.702 2.365 & $<0.001$ & 1.201 & $0.932 \sim 1.549$ & 0.157 \\
\hline \multicolumn{7}{|l|}{ Glasgow prognostic score } \\
\hline 0 & Reference & & & & & \\
\hline I & 0.892 & $0.370 \sim 2.154$ & 0.800 & & & \\
\hline 2 & 1.719 & $0.707 \sim 4.180$ & 0.232 & & & \\
\hline \multicolumn{7}{|l|}{ SII } \\
\hline$<940$ & Reference & & & & & \\
\hline$\geq 940$ & 2.187 & I.846 2.59| & $<0.001$ & 1.395 & $1.064 \sim 1.829$ & 0.016 \\
\hline \multicolumn{7}{|l|}{ Nutritional status } \\
\hline Normally nourished & Reference & & & & & \\
\hline Malnutrition stage I & 1.202 & $1.006 \sim 1.438$ & 0.043 & & & \\
\hline Malnutrition stage II & 1.678 & I.354 2.08। & $<0.001$ & & & \\
\hline
\end{tabular}

Abbreviations: Alb, albumin; CRP, C-reactive protein; NLR, neutrophil to lymphocyte ratio; SIl, systemic immune-inflammation index. 


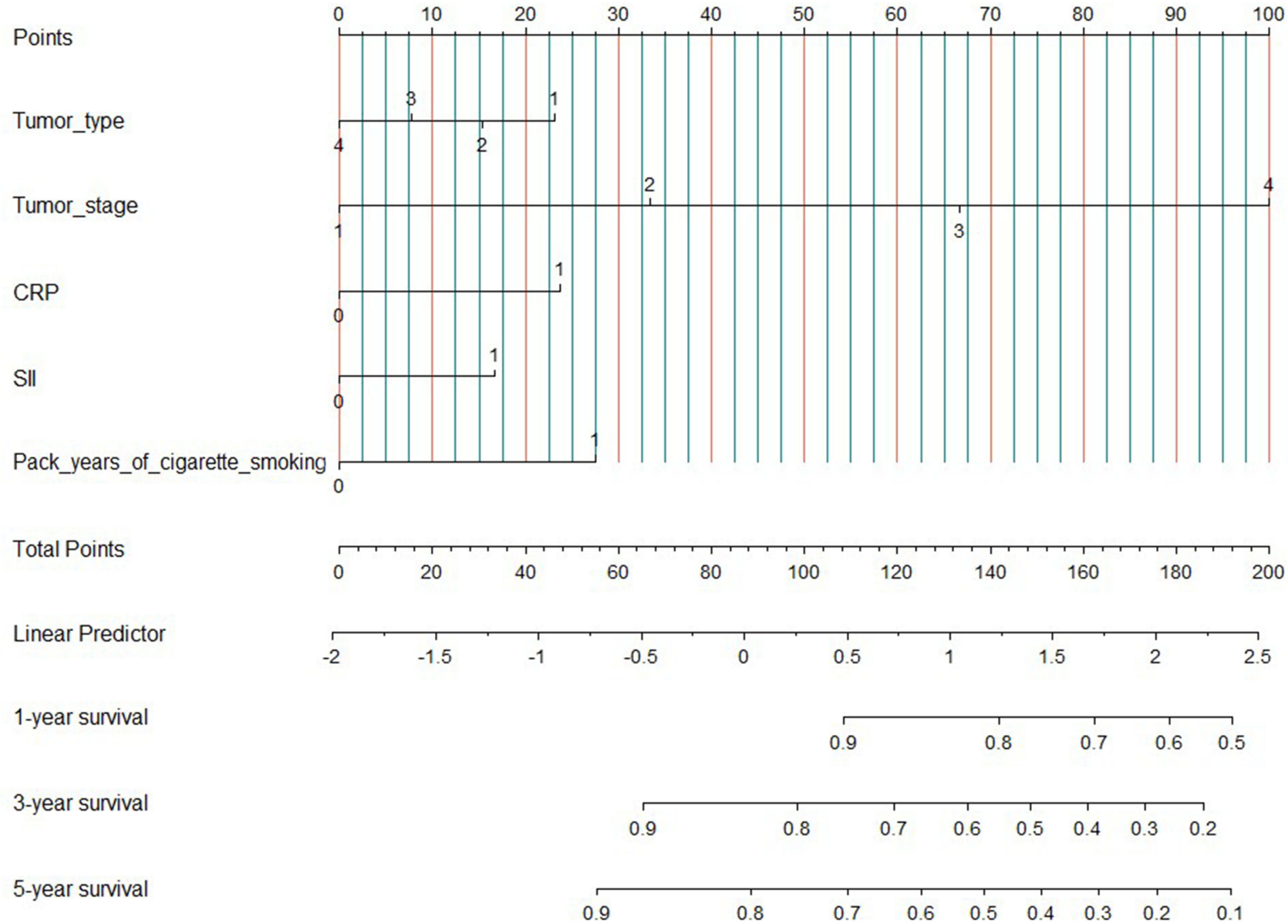

Figure I The scored-inflammatory marker system by nomogram used to quantize the inflammation-related markers.

Notes: Tumor type: I = Digestive system neoplasms; 2 = Lung cancer; 3 = Breast cancer; 4 = Gynecologic oncology. Tumor stage: I = I; 2 = II; 3 = III; 4 = IV. CRP: 0 = CRP $<5 \mathrm{mg} / \mathrm{L} ;$ I $=$ CRP $\geq 5 \mathrm{mg} / \mathrm{L}$. SII: $0=$ SII $<940 ;$ I = SII $\geq 940$. Pack years of cigarette smoking: $0=$ Pack years of cigarette smoking $<8 ;$ I = Pack years of cigarette smoking $\geq 8$.

A was associated with the risk of malnutrition stage II (HR $1.951,95 \%$ CI of HR 1.136-3.351, $\mathrm{P}=0.015$ ) (Table 5).

\section{Discussion}

The global burden of cancer has continued to increase rapidly, which reflects both population growth and aging. In a recent global survey, cancer has remained to be the leading cause of death; ${ }^{1}$ thus, an optimization of cancer management is imperative. Local or systemic inflammation is considered a possible "precancerous lesion" especially in the setting of long-term chronic inflammation, which is regarded as one of the hallmarks of cancer. ${ }^{27}$ Numerous studies ${ }^{28-30}$ have shown that a large proportion of malignant tumors is promoted by reactive oxygen species (ROS), nitric oxide synthase released by inflammatory cells, or inflammatory cytokines, such as IL-6 and TNF- $\alpha$. Major inflammatory pathways that are involved in inflammation-induced carcinogenesis converge at the transcription factors signal transducer and activator of transcription
3 (STAT3) and subsequent NF-кB. The activation of STAT members, particularly STAT3, is broadly implicated in tumorigenesis, and is closely linked to inflammatory processes in colon, lung and pancreatic cancers. ${ }^{31-33}$ In addition, inflammation may have a prominent role in initiating neoplastic transformation by increasing the rates of DNA damage while compromising DNA repair mechanisms.

Inflammation is not an independent part. Patients with malignant tumors often experience abnormal energy metabolism and severe depletion, in which inflammatory cytokines also play a key role and results in malnutrition and worsens clinical outcomes. ${ }^{34-36}$ Cytokines including IL-6, TNF- $\alpha$ and TGF $\beta$ activate abnormal metabolic pathways, including increased proteolysis, decreased amino acid transport and regeneration, ${ }^{37}$ regulating endocrine pathways such as glucagon and adrenocorticotropic hormone. $^{38,39}$ Among these, IL-6 is an essential factor as it stimulates the degradation of muscle and fats. ${ }^{40}$ Strassmann et $\mathrm{al}^{41}$ reported that anti-IL-6 treated mice 


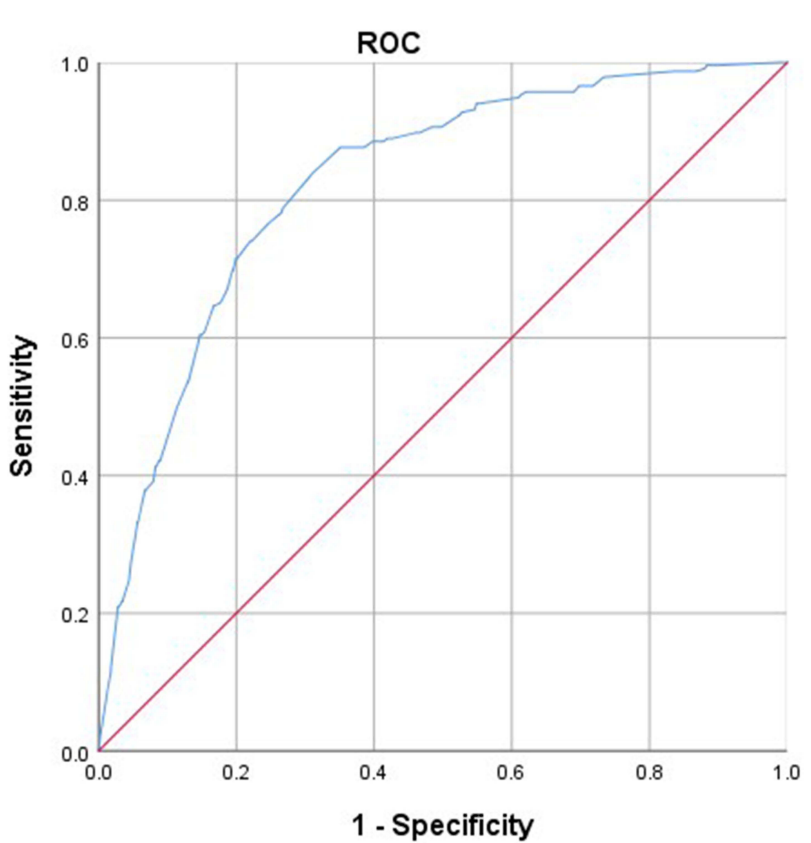

A

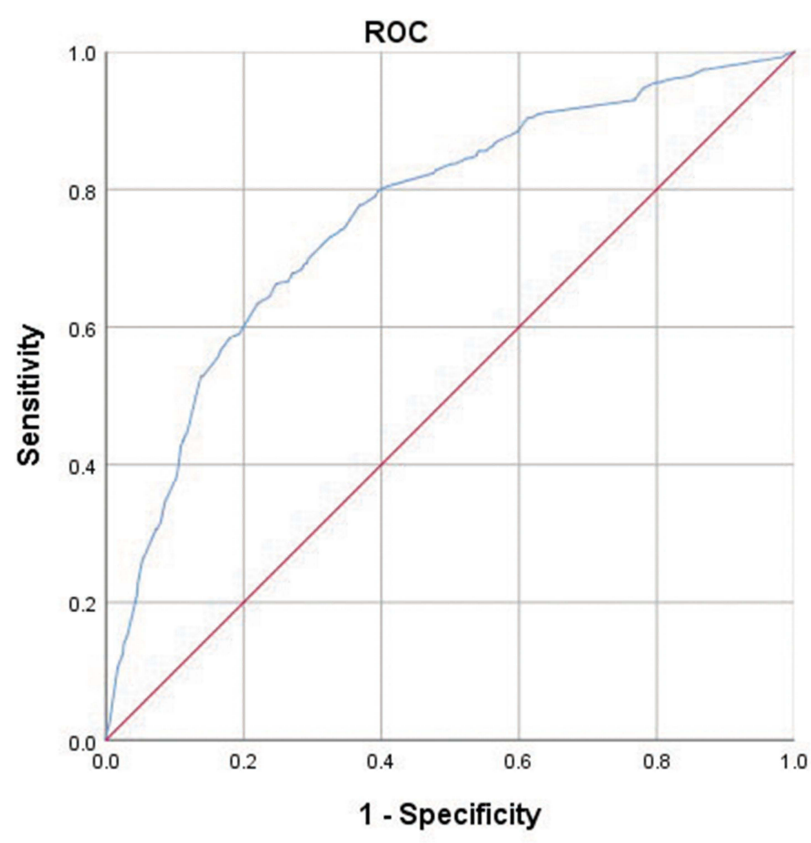

B

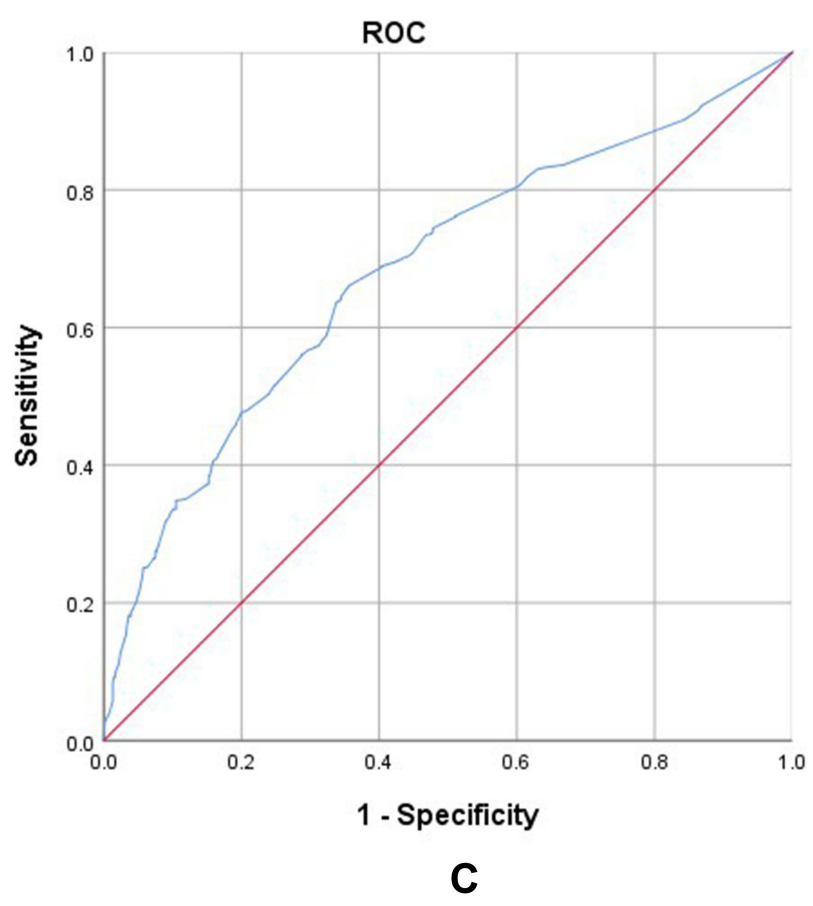

Figure 2 (A-C) Area under the ROC curves (AUC) for predicting the overall survival at I, 3, and 5 years in the primary cohort.

significantly recovered from LPS-induced weight loss, and the monoclonal antibody against IL-6 could also prevent muscle and adipose tissue loss caused by chronic inflammation. IL-6 participants in the classical signaling pathway of systemic inflammatory response, particularly upregulating the synthesis of the hepatic acute phase protein CRP. That is, IL- 6 behaves as a bridge linking nutritional status and inflammation.
Due to the close relationship between cancer, inflammation and malnutrition, it seems feasible to establish prognostic predicting models using systemic inflammatory parameters. A variety of inflammatory cells, including neutrophils, lymphocytes, and platelets, as well as other factors, such as CRP, have been determined to be associated with prognosis in patients with various cancers. $^{42}$ Among them, CRP is the most common 


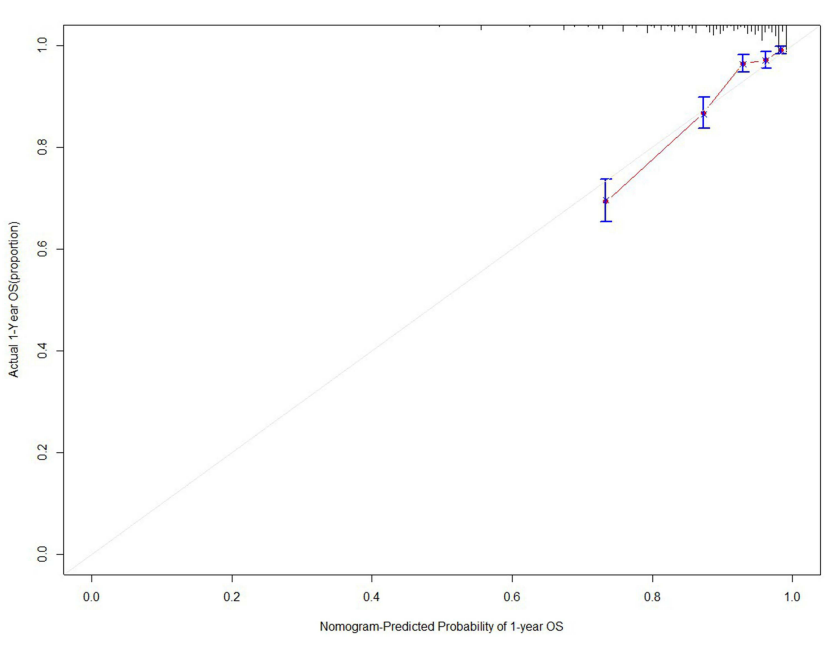

A

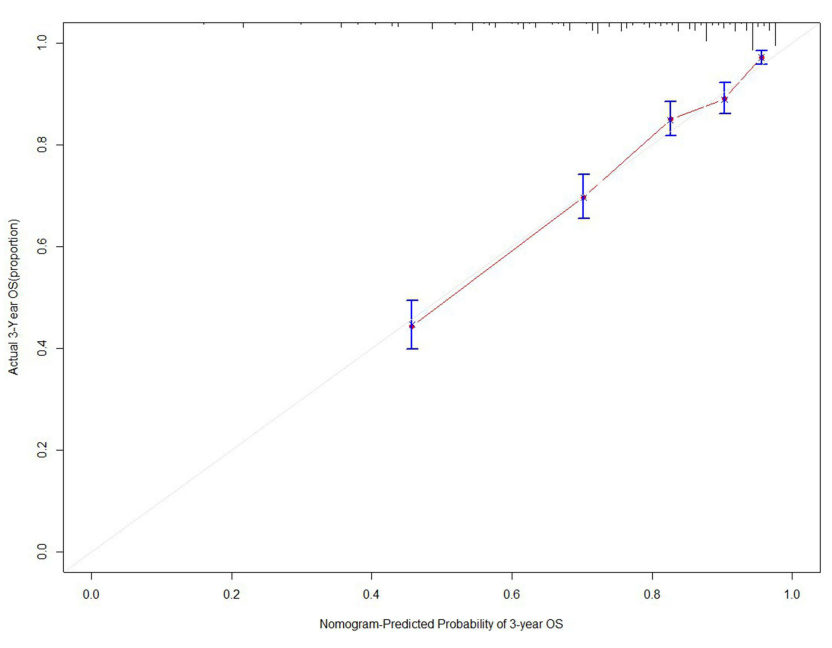

B

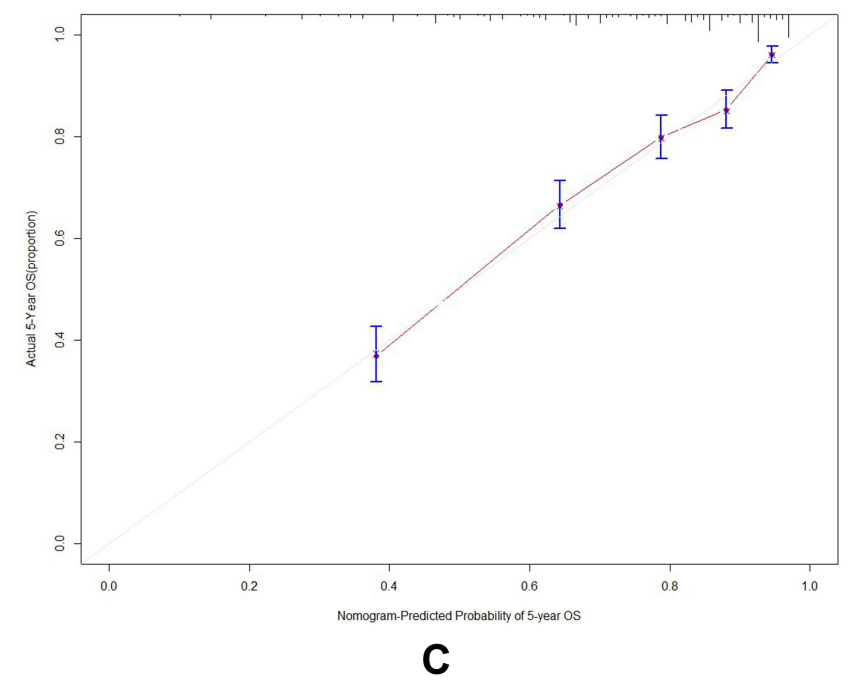

Figure 3 (A-C) Calibration curves of primary cohort for the nomogram predictions of the 1-, 3- and 5-year overall survival.

Notes: (A) Calibration curves of primary cohort for the nomogram predictions of the I-year overall survival; (B) calibration curves of primary cohort for the nomogram predictions of the 3-year overall survival; (C) calibration curves of primary cohort for the nomogram predictions of the 5-year overall survival.

objective indicator. As a downstream product, CRP also partially represents the level of IL-6. The Glasgow Prognostic Score, which comprises CRP and Alb, is frequently used as a parameter to evaluate inflammation burden. ${ }^{17}$ NLR has been demonstrated to be significantly associated with patient prognosis in multiple cancers, such as lung, gastric, breast, and ovarian cancers, ${ }^{43-46}$ but negative results were obtained in this study. SII, combined platelets with NLR is also considered a prognostic factor in patients with solid tumors. ${ }^{47,48}$ Inflammation plays an important role in tumor initiation by destroying specific tissues, and neutrophils are considered an important component of this process. Studies have shown that neutrophils play a priming role through their attraction to tumor-prone tissues through different
CXC-chemokines, as impaired neutrophil trafficking and inhibited tumor formation in mouse models with defective CXCR2 expression. ${ }^{49}$ The production of ROS and reactive nitrogen species by neutrophils, as well as angiogenic factors such as MMP9, also have been deemed vital in tumor initiation. ${ }^{50}$ Moreover, neutrophils can induce angiogenesis ${ }^{51,52}$ and participate in the escape of cancer cells from the primary tumor, ${ }^{53}$ thus they further promote tumor growth and metastasis. Platelet-derived transforming growth factor $\beta 1$ (TGF $\beta 1$ ) is necessary for the metastasis of tumor cells in vivo. ${ }^{54}$ Taken together, it is expected that patients with elevated neutrophil and platelet counts and decreased lymphocyte counts, which are indicative of a high SII, would have a worse tumor prognosis. 


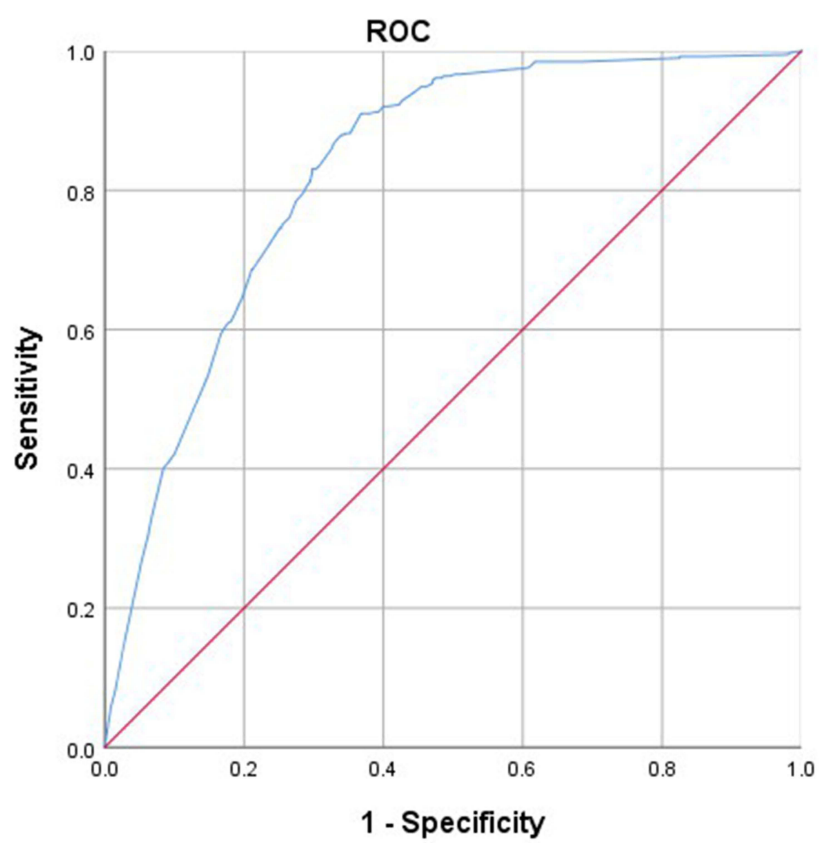

A

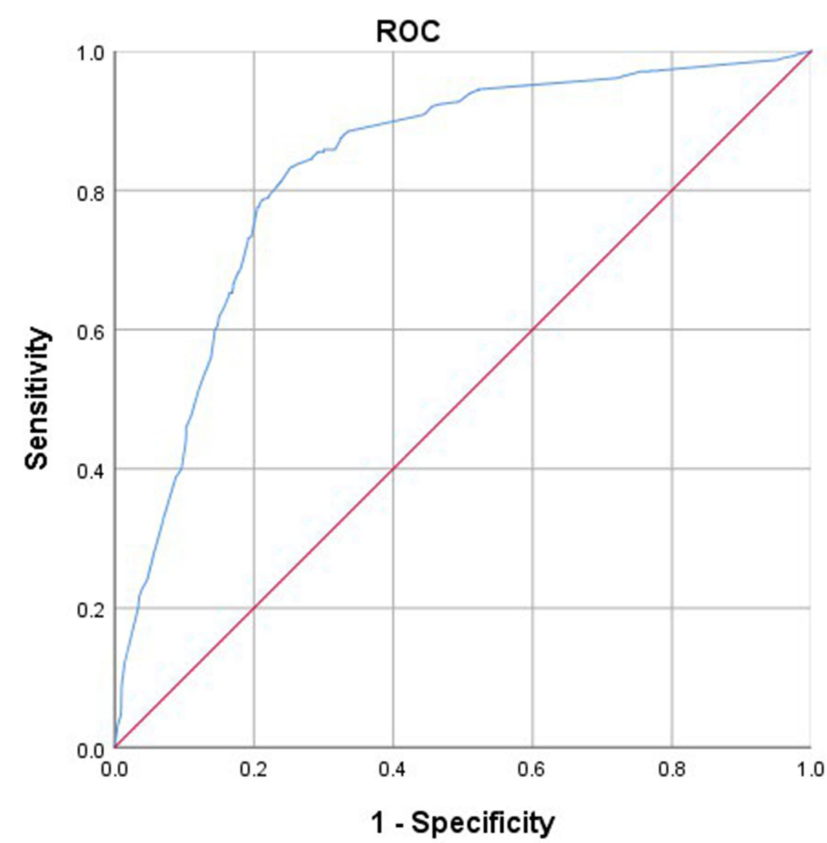

B

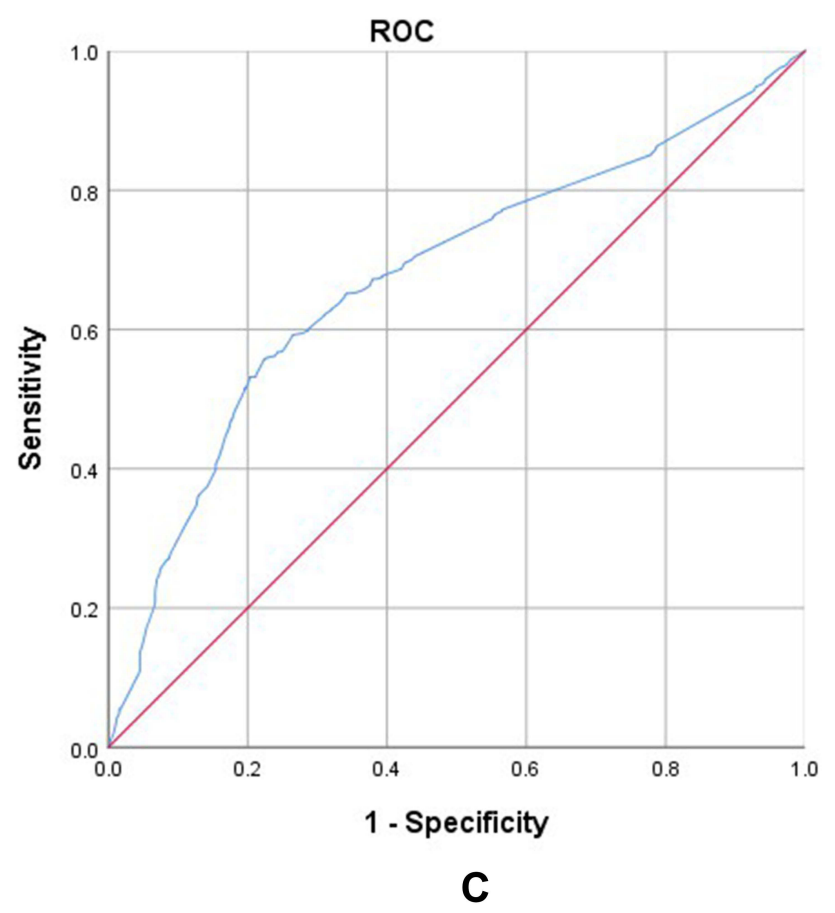

Figure 4 (A-C) Area under the ROC curves (AUC) for predicting the overall survival at I, 3, and 5 years in the validation cohort.

In the selection of the above exploratory indicators, the accessibility of indicators was considered. Basic clinical data, and serological indicators were primarily selected given the convenient acquisition and reproducibility, and thus can provide guidance for extensive clinical work. In addition, the smoking status of patients was also explored in this study. On the one hand, the National Comprehensive Cancer Network guidelines have indicated that smoking is a risk factor in tumors, such as lung cancer, esophageal cancer, and pancreatic cancer. However, the length of smoking history and the dose of smoking are not mentioned in the relevant guidelines. On the other hand, smoking can induce acute and chronic inflammatory responses in the body and thus promote the production of key inflammatory cytokines, such as IL-6 and IL-8, thereby causing subsequent pathological 


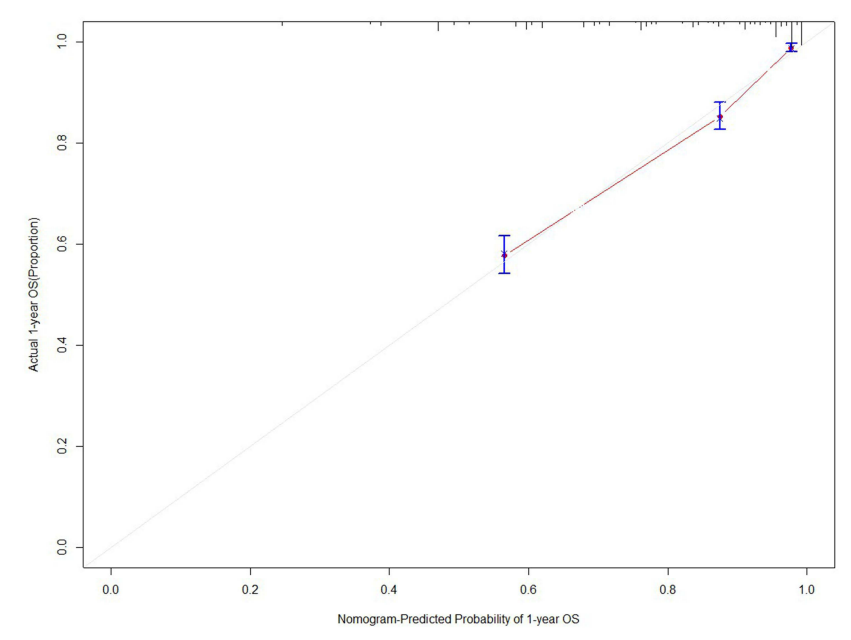

A

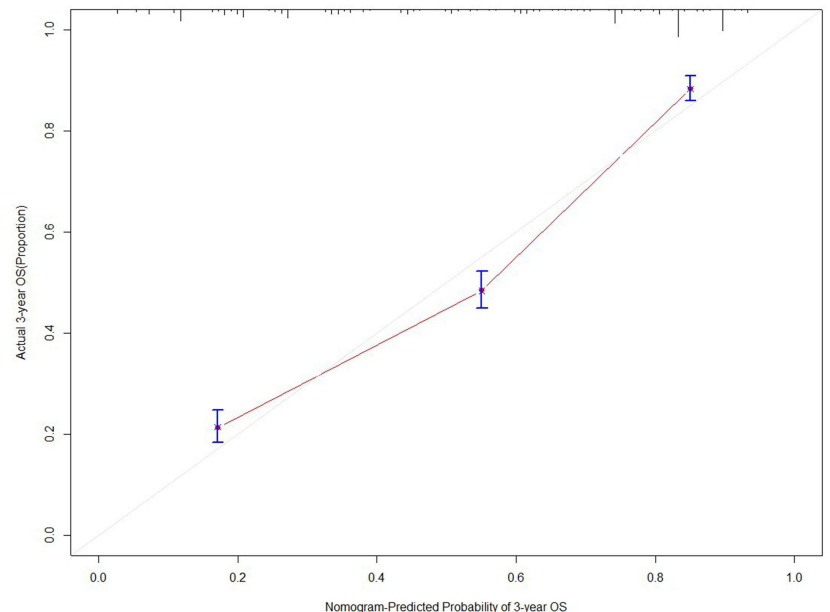

B

Figure 5 (A-C) Calibration curves of validation cohort for the nomogram predictions of the I-, 3- and 5-year overall survival.

Notes: (A) Calibration curves of validation cohort for the nomogram predictions of the I-year overall survival; (B) calibration curves of validation cohort for the nomogram predictions of the 3-year overall survival; (C) calibration curves of validation cohort for the nomogram predictions of the 5-year overall survival.

changes. $^{55-57}$ Therefore, we believe that the smoking status of patients should also be regarded as a non-serological objective indicator when we explore malignant tumor-

Table 3 Inflammatory Models Formed After Combining PackYears of Cigarette Smoking, CRP, and SII

\begin{tabular}{|l|c|c|c|c|c|c|c|c|}
\hline \multirow{2}{*}{ Inflammatory Makers } & \multicolumn{7}{|c|}{ Inflammatory Models } \\
\cline { 2 - 8 } & A & B & C & D & E & F & G & H \\
\hline Pack-years of cigarette & + & + & + & + & - & - & - & - \\
smoking & & & & & & & & \\
CRP & + & + & - & - & + & + & - & - \\
SII & + & - & - & + & + & - & + & - \\
\hline
\end{tabular}

Notes: The cut-off value for pack-years of cigarette smoking, CRP and SII was 8, 5 and 940 , respectively. An inflammatory marker that meets the high value is regarded as positive (+), whereas an inflammatory marker that meets the low value is regarded as negative $(-)$. related inflammatory markers. Smoking is not only a cause of inflammation, but it also potentially reflects possible differences in mutation burden in cancer patients. Govindan $\mathrm{R}$ et $\mathrm{al}^{58}$ compared the results of whole-genome and transcriptome sequencing of tumor tissues from smokers versus non-smokers with non-small cell lung cancer and found that smokers had ten times higher average frequency of genetic mutations than never-smokers. Correspondingly, the study by Chae et $\mathrm{al}^{59}$ also reported that smoking history is associated with elevated tumor mutational burden (TMB), and a high TMB often predicts poor clinical outcomes. Therefore, smoking implies differences in clinical outcomes from both the inflammatory and the genetic perspective.

Various inflammatory indicators were combined and their efficacy in prognosis was compared in this study. 
Table 4 Univariable Cox Regression of 8 Inflammatory Models with Mortality of Cancer Patients in Primary Cohort

\begin{tabular}{|c|c|c|c|}
\hline Models & HR & $95 \% \mathrm{Cl}$ of $\mathrm{HR}$ & $\mathbf{P}$ \\
\hline \multicolumn{4}{|l|}{ Overall } \\
\hline A & 6.228 & $4.744 \sim 8.175$ & $<0.001$ \\
\hline B & 5.416 & $4.079 \sim 7.192$ & $<0.001$ \\
\hline C & 2.795 & $2.174 \sim 3.593$ & $<0.001$ \\
\hline $\mathrm{D}$ & 5.580 & $3.766 \sim 8.269$ & $<0.001$ \\
\hline$E$ & 3.651 & $2.745 \sim 4.855$ & $<0.001$ \\
\hline $\mathrm{F}$ & 2.894 & $2.122 \sim 3.947$ & $<0.001$ \\
\hline G & 2.090 & $1.352 \sim 3.232$ & 0.001 \\
\hline \multicolumn{4}{|l|}{ Specific of tumor type } \\
\hline \multicolumn{4}{|l|}{ Lung cancer } \\
\hline A & 3.442 & $2.363 \sim 5.012$ & $<0.001$ \\
\hline B & 2.625 & $1.812 \sim 3.803$ & $<0.001$ \\
\hline C & 1.387 & $0.978 \sim 1.967$ & 0.660 \\
\hline $\mathrm{D}$ & 2.964 & $1.806 \sim 4.864$ & $<0.001$ \\
\hline $\mathrm{E}$ & 2.651 & $1.740 \sim 4.038$ & $<0.001$ \\
\hline $\mathrm{F}$ & 2.025 & $1.302 \sim 3.148$ & 0.002 \\
\hline G & 0.970 & $0.442 \sim 2.131$ & 0.940 \\
\hline \multicolumn{4}{|l|}{ Breast cancer } \\
\hline A & 18.506 & $7.408 \sim 46.232$ & $<0.001$ \\
\hline B & 10.247 & $2.405 \sim 43.664$ & 0.002 \\
\hline C & 3.432 & I.180 9.983 & 0.024 \\
\hline $\mathrm{D}$ & 10.058 & $2.354 \sim 42.974$ & 0.002 \\
\hline $\mathrm{E}$ & 0.784 & $0.106 \sim 5.809$ & 0.812 \\
\hline $\mathrm{F}$ & 3.533 & $1.217 \sim 10.26 \mathrm{I}$ & 0.020 \\
\hline G & 2.761 & $0.824 \sim 9.244$ & 0.100 \\
\hline \multicolumn{4}{|l|}{ Digestive system neoplasms } \\
\hline A & 2.492 & $1.532 \sim 4.053$ & $<0.001$ \\
\hline B & 2.163 & $1.215 \sim 3.852$ & 0.009 \\
\hline C & 1.363 & $0.877 \sim 2.119$ & 0.169 \\
\hline $\mathrm{D}$ & $\mathrm{I} .88 \mathrm{I}$ & $0.798 \sim 4.436$ & 0.149 \\
\hline $\mathrm{E}$ & 2.110 & $1.327 \sim 3.354$ & 0.002 \\
\hline $\mathrm{F}$ & 1.129 & $0.626 \sim 2.036$ & 0.687 \\
\hline G & 1.311 & $0.616 \sim 2.793$ & 0.482 \\
\hline \multicolumn{4}{|l|}{ Gynecologic oncology } \\
\hline A & 2.026 & $0.256 \sim 16.024$ & 0.503 \\
\hline B & 1.508 & $0.190 \sim 11.990$ & 0.698 \\
\hline C & 1.297 & $0.164 \sim 10.256$ & 0.805 \\
\hline $\mathrm{D}$ & 46.451 & $5.274 \sim 409.090$ & 0.001 \\
\hline $\mathrm{E}$ & 2.714 & $0.96 \mathrm{I} \sim 7.659$ & 0.059 \\
\hline $\mathrm{F}$ & 3.483 & $1.338 \sim 9.070$ & 0.011 \\
\hline G & 4.556 & $1.608 \sim 12.908$ & 0.004 \\
\hline
\end{tabular}

Note: Taking inflammatory model $\mathrm{H}$ as reference group. Abbreviations: $\mathrm{Cl}$, confidence interval; $\mathrm{HR}$, hazard ratio.

A scored-inflammatory marker system was constructed consisting of tumor type, tumor stage, pack-years of cigarette smoking, CRP, and SII. As seen in the results, our scored-inflammatory marker system obtained an excellent efficacy in predicting the probability of survival at each time point among cancer patients. Both in primary cohort and in validation cohort, the predicted survival probabilities closely corresponded to the actual survival probabilities. To further explore a useful inflammatory model, eight inflammatory models were developed based on a combination of CRP, SII, and pack-years of cigarette smoking. Among all enrolled participants, it was clear that model $\mathrm{H}$, in which all inflammatory markers were negative, was associated with significantly longer OS. On the contrary, patients in model A (pack-years of cigarette smoking $\geq 8$ packs $\times$ years, $C R P \geq 5 \mathrm{mg} / \mathrm{L}, \mathrm{SII} \geq 940$ ) had the worst prognosis and the shortest OS. In subanalysis of specific tumor types, patients stratified into model A still had the highest risk of death in lung cancer, breast cancer and digestive system neoplasms. In gynecologic oncology subgroup, model D presented the highest risk with a large range of confidential interval. A relatively small number of gynecologic oncology patients (169 cases, occupied 6.9\% of all participants) was inferred as the main reason, since it did not adequately represent the overall situation, and also resulted in the potentially inaccurate statistical results. In that case, subsequent studies with larger sample size are necessary.

Given the inextricable correlations among inflammation and nutritional status, the insights of inflammation and malnutrition must be paid attention. The GLIM guidelines $^{26}$ clearly suggest that inflammation is a diagnostic criterion for malnutrition, but quantitative evaluation of various inflammatory markers remains to be lacking. Among the various inflammatory indicators, it is not clear which indicator is the most valuable for the evaluation of malnutrition. In our study, the relationship between the degree of inflammation and nutritional status was investigated, and the results supported the view that increased systemic inflammation can significantly increase the risk of malnutrition. The model A also confirmed an effective indicator of malnutrition. In addition, our results once again confirm that patients with digestive system tumors are at higher risk of malnutrition compared with patients with lung, breast, and gynecological tumors. This is largely due to the tumor mass effect and digestive tract dysfunction, while the occurrence of malnutrition in other cancers is caused by a combination of systemic factors. ${ }^{60,61}$

As a real-world clinical study with prognosis and malnutrition as the outcome variables, our study comprehensively reflects the overall situation of cancer patients to some extent. Although previous studies ${ }^{14,62,63}$ have 

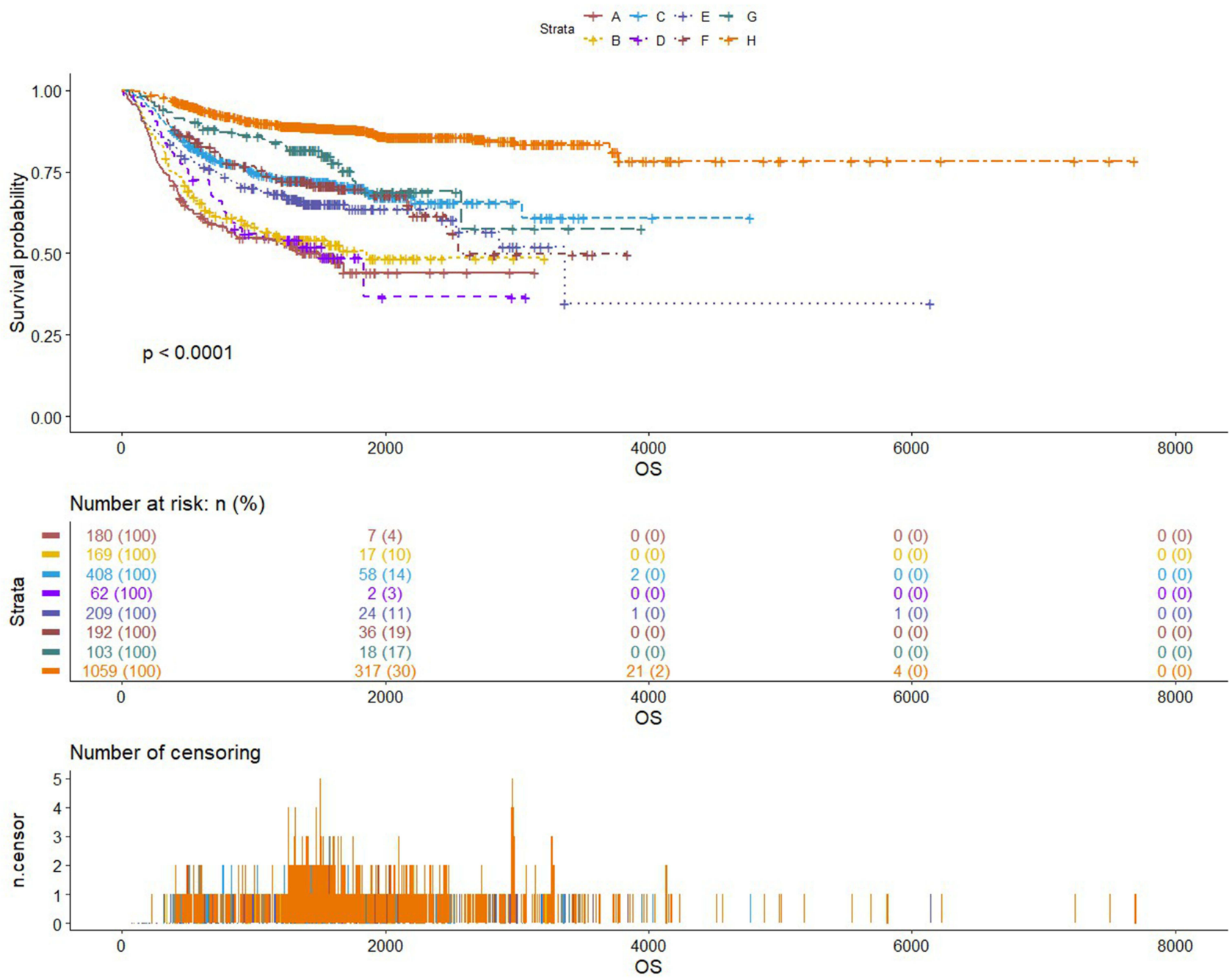

Figure 6 Kaplan-Meier curve of all patients with different inflammatory status in primary cohort.

explored the use of inflammatory markers for prognostic prediction in patients with malignant tumors, there were certain limitations. First of all, there has been controversy about the choice of markers that best reflect inflammatory conditions. The indicators proposed by different studies are not same. Second, whether a single indicator has sufficient power for predicting prognosis also deserves investigations. To settle these limitations, the optimal cutoff values of these inflammatory markers were proposed in this study, and a scored-inflammatory marker system was established, which was validated with good prediction ability. What is more, our results indicated that Model A, which was positive for pack-years of cigarette smoking, SII and CRP, obtained predictive efficacy in both prognosis and malnutrition, and can be easily used in clinical practice. This study also has certain limitations. First, as a retrospective study, this study may have some data bias;
Second, there was a small number of certain cancer patients, such as gynecologic oncology; thus, in the future, a subsequent study with larger sample size is necessary.

\section{Conclusion}

In summary, this study defined the optimal cut-off values of inflammatory markers for predicting prognosis of patients with malignancies. For the first time, a scoredinflammatory marker system was constructed, which is capable of properly identifying a patient with high mortality risk from patients with the same type and stage of cancer. Proper inflammatory models of survival and malnutrition evaluation of patients were established. The construction of the models partially fills gaps in the field of cancer, chronic inflammatory response and nutrition, which provides a basis for subsequent studies. We expect that the scored-inflammatory marker system and 
Table 5 Logistic Regression of Inflammatory Model A and Nutritional Status of Cancer Patients

\begin{tabular}{|c|c|c|c|}
\hline \multicolumn{2}{|l|}{ Relevant Factors } & \multirow{2}{*}{$\frac{\text { OR (95\% Cl of OR) }}{1.759(1.409 \sim 2.197)}$} & \multirow{2}{*}{$\begin{array}{c}\mathbf{P} \\
<0.001\end{array}$} \\
\hline Malnutrition & Age & & \\
\hline & Gender & I.I 77 (0.902 I.535) & 0.306 \\
\hline & $\begin{array}{l}\text { Tumor type } \\
\text { Lung cancer } \\
\text { Breast cancer } \\
\text { Gynecologic oncology }\end{array}$ & $\begin{array}{l}0.457(0.354 \sim 0.591) \\
0.338(0.247 \sim 0.463) \\
0.696(0.453 \sim 1.070)\end{array}$ & $\begin{array}{l}<0.001 \\
<0.001 \\
0.098\end{array}$ \\
\hline & $\begin{array}{l}\text { Tumor stage } \\
\text { II } \\
\text { III } \\
\text { IV }\end{array}$ & $\begin{array}{l}1.298(1.005 \sim 1.677) \\
I .163(0.901 \sim 1.50 \mathrm{I}) \\
\mathrm{I} .493(\mathrm{I} . \mathrm{I} 17 \sim 1.994)\end{array}$ & $\begin{array}{l}0.046 \\
0.245 \\
0.007\end{array}$ \\
\hline & Nutritional support & $1.272(0.989 \sim 1.636)$ & 0.061 \\
\hline & Inflammatory model A & I.63। (1.054 2.467) & 0.027 \\
\hline \multirow[t]{6}{*}{ Malnutrition stage I } & Age & $1.740(1.382 \sim 2.192)$ & $<0.001$ \\
\hline & Gender & $1.184(0.908 \sim 1.545)$ & 0.212 \\
\hline & $\begin{array}{l}\text { Tumor type } \\
\text { Lung cancer } \\
\text { Breast cancer } \\
\text { Gynecologic oncology }\end{array}$ & $\begin{array}{l}0.753(0.483 \sim 1.176) \\
0.518(0.396 \sim 0.678) \\
0.369(0.267 \sim 0.5 \mathrm{I} 2)\end{array}$ & $\begin{array}{l}0.212 \\
<0.001 \\
<0.001\end{array}$ \\
\hline & $\begin{array}{l}\text { Tumor stage } \\
\text { II } \\
\text { III } \\
\text { IV }\end{array}$ & $\begin{array}{l}1.166(0.892 \sim 1.523) \\
\text { I.I I }(0.854 \sim 1.45 \mathrm{I}) \\
\mathrm{I} .389(\mathrm{I} .026 \sim 1.880)\end{array}$ & $\begin{array}{l}0.261 \\
0.429 \\
0.033\end{array}$ \\
\hline & Nutritional support & $1.236(0.950 \sim 1.607)$ & 0.114 \\
\hline & Inflammatory model A & $1.507(0.967-2.347)$ & 0.070 \\
\hline \multirow[t]{6}{*}{ Malnutrition stage II } & Age & 1.815 (1.355 2.432) & $<0.001$ \\
\hline & Gender & $1.026(0.731 \sim 1.439)$ & 0.883 \\
\hline & $\begin{array}{l}\text { Tumor type } \\
\text { Lung cancer } \\
\text { Breast cancer } \\
\text { Gynecologic oncology }\end{array}$ & $\begin{array}{l}0.536(0.296 \sim 0.97 I) \\
0.339(0.242 \sim 0.475) \\
0.247(0.159 \sim 0.383)\end{array}$ & $\begin{aligned} & 0.04 \\
< & 0.001 \\
< & 0.001\end{aligned}$ \\
\hline & $\begin{array}{l}\text { Tumor stage } \\
\text { II } \\
\text { III } \\
\text { IV }\end{array}$ & $\begin{array}{l}1.949(1.3 \mathrm{I} I \sim 2.898) \\
1.452(0.975 \sim 2.163) \\
2.07 \mathrm{I}(\mathrm{I} .345 \sim 3.190)\end{array}$ & $\begin{array}{l}0.001 \\
0.066 \\
0.001\end{array}$ \\
\hline & Nutritional support & $1.413(1.017 \sim 1.962)$ & 0.039 \\
\hline & Inflammatory model A & $1.951(1.136-3.351)$ & 0.015 \\
\hline
\end{tabular}

Notes: Confounders were gender, age, tumor type, tumor stage, nutritional support, and inflammatory models. Taking age $<65$, male, digestive system neoplasms, tumor stage I, no nutritional support, inflammatory model $\mathrm{H}$ as reference, respectively. 
inflammatory models will be applied in clinical practice to provide convenience and assistance.

\section{Data Sharing Statement}

Materials described in the manuscript, including all relevant raw data, will be freely available to any scientist wishing to use them for non-commercial purposes, without breaching participant confidentiality.

\section{Ethics Approval and Consent to Participate}

The study was approved by the Ethics Committee of the first affiliated hospital of Jilin University (2017-362), and all the patient data in this research was approved by this committee. All study participants have filled out written informed consent for participation.

\section{Funding}

This work was supported by National Key R\&D Program of China (2016YFC1303804).

\section{Disclosure}

There is no relevant conflict of interest.

\section{References}

1. Sung H, Ferlay J, Siegel RL, et al. Global cancer statistics 2020: GLOBOCAN estimates of incidence and mortality worldwide for 36 cancers in 185 countries. CA Cancer J Clin. 2021;71(3):209-249. doi: $10.3322 /$ caac. 21660

2. Omran AR. The epidemiologic transition: a theory of the epidemiology of population change. 1971. Milbank Q. 2005;83(4):731-757. doi:10.1111/j.1468-0009.2005.00398.x

3. Bray F, Laversanne M, Weiderpass E, et al. The ever-increasing importance of cancer as a leading cause of premature death worldwide. Cancer. 2021. doi:10.1002/cncr.33587

4. Zugazagoitia J, Guedes C, Ponce S, et al. Current challenges in cancer treatment. Clin Ther. 2016;38(7):1551-1566. doi:10.1016/j. clinthera.2016.03.026

5. Balkwill F, Mantovani A. Inflammation and cancer: back to Virchow? Lancet. $\quad 2001 ; 357(9255): 539-545 . \quad$ doi:10.1016/S0140-6736(00) 04046-0

6. Diakos CI, Charles KA, Mcmillan DC, et al. Cancer-related inflammation and treatment effectiveness. Lancet Oncol. 2014;15(11):e493503. doi:10.1016/S1470-2045(14)70263-3

7. Candido J, Hagemann T. Cancer-related inflammation. $J$ Clin Immunol. 2013;33(Suppl 1):S79-S84. doi:10.1007/s10875-0129847-0

8. Hanahan D, Weinberg RA. Hallmarks of cancer: the next generation. Cell. 2011;144(5):646-674. doi:10.1016/j.cell.2011.02.013

9. Dranoff G. Cytokines in cancer pathogenesis and cancer therapy. Nat Rev Cancer. 2004;4(1):11-22. doi:10.1038/nrc1252

10. Renner P, Roger T, Calandra T. Macrophage migration inhibitory factor: gene polymorphisms and susceptibility to inflammatory diseases. Clin Infect Dis. 2005;41(Suppl 7):S513-519. doi:10.1086/ 432009
11. Karin M, Greten FR. NF-kappaB: linking inflammation and immunity to cancer development and progression. Nat Rev Immunol. 2005;5(10):749-759. doi:10.1038/nri1703

12. Holcomb B, Yip-schneider M, Schmidt CM. The role of nuclear factor kappaB in pancreatic cancer and the clinical applications of targeted therapy. Pancreas. 2008;36(3):225-235. doi:10.1097/ MPA.0b013e31815b3207

13. Mcmillan DC. The systemic inflammation-based Glasgow Prognostic Score: a decade of experience in patients with cancer. Cancer Treat Rev. 2013;39(5):534-540. doi:10.1016/j.ctrv.2012.08.003

14. Saito K, Kihara K. C-reactive protein as a biomarker for urological cancers. Nat Rev Urol. 2011;8(12):659-666. doi:10.1038/ nrurol.2011.145

15. Leitch EF, Chakrabarti M, Crozier JE, et al. Comparison of the prognostic value of selected markers of the systemic inflammatory response in patients with colorectal cancer. Br J Cancer. 2007;97 (9):1266-1270. doi:10.1038/sj.bjc.6604027

16. Cupp MA, Cariolou M, Tzoulaki I, et al. Neutrophil to lymphocyte ratio and cancer prognosis: an umbrella review of systematic reviews and meta-analyses of observational studies. BMC Med. 2020;18 (1):360. doi:10.1186/s12916-020-01817-1

17. Douglas E, Mcmillan DC. Towards a simple objective framework for the investigation and treatment of cancer cachexia: the Glasgow Prognostic Score. Cancer Treat Rev. 2014;40(6):685-691. doi:10.1016/j.ctrv.2013.11.007

18. Hu B, Yang XR, Xu Y, et al. Systemic immune-inflammation index predicts prognosis of patients after curative resection for hepatocellular carcinoma. Clin Cancer Res. 2014;20(23):6212-6222. doi:10.1158/1078-0432.CCR-14-0442

19. Meza-valderrama D, Marco E, Dávalos-yerovi V, et al. Sarcopenia, malnutrition, and cachexia: adapting definitions and terminology of nutritional disorders in older people with cancer. Nutrients. 2021;13 (3):761. doi:10.3390/nu13030761

20. Cederholm TE, Hellström KH. Reversibility of protein-energy malnutrition in a group of chronically-ill elderly outpatients. Clin Nutr. 1995;14(2):81-87. doi:10.1016/S0261-5614(95)80027-1

21. Yeh SS, Schuster MW. Geriatric cachexia: the role of cytokines. $A m$ J Clin Nutr. 1999;70(2):183-197. doi:10.1093/ajen.70.2.183

22. Reid MB, Li YP. Tumor necrosis factor-alpha and muscle wasting: a cellular perspective. Respir Res. 2001;2(5):269-272. doi:10.1186/ rr67

23. Mcmillan DC. Systemic inflammation, nutritional status and survival in patients with cancer. Curr Opin Clin Nutr Metab Care. 2009;12 (3):223-226. doi:10.1097/MCO.0b013e32832a7902

24. Kao SC, Pavlakis N, Harvie R, et al. High blood neutrophil-tolymphocyte ratio is an indicator of poor prognosis in malignant mesothelioma patients undergoing systemic therapy. Clin Cancer Res. 2010;16(23):5805-5813. doi:10.1158/1078-0432.CCR-10-2245

25. Singh R, Mishra MK, Aggarwal H. Inflammation, immunity, and cancer. Mediators Inflamm. 2017;2017:6027305. doi:10.1155/2017/ 6027305

26. Jensen GL, Cederholm T, Correia M, et al. GLIM criteria for the diagnosis of malnutrition: a consensus report from the global clinical nutrition community. JPEN J Parenter Enteral Nutr. 2019;43 (1):32-40. doi:10.1002/jpen.1440

27. Shacter E, Weitzman SA. Chronic inflammation and cancer. Oncology (Williston Park). 2002;16(2):217-226, 229; discussion 230-212.

28. Maeda H, Akaike T. Nitric oxide and oxygen radicals in infection, inflammation, and cancer. Biochemistry (Mosc). 1998;63(7):854-865.

29. Federico A, Morgillo F, Tuccillo C, et al. Chronic inflammation and oxidative stress in human carcinogenesis. Int $J$ Cancer. 2007;121 (11):2381-2386. doi:10.1002/ijc. 23192

30. Taniguchi K, Karin M. IL-6 and related cytokines as the critical lynchpins between inflammation and cancer. Semin Immunol. 2014;26(1):54-74. 
31. Grivennikov S, Karin E, Terzic J, et al. IL-6 and Stat3 are required for survival of intestinal epithelial cells and development of colitis-associated cancer. Cancer Cell. 2009;15(2):103-113. doi:10.1016/j.ccr.2009.01.001

32. Lesina M, Kurkowski MU, Ludes K, et al. Stat3/Socs3 activation by IL-6 transsignaling promotes progression of pancreatic intraepithelial neoplasia and development of pancreatic cancer. Cancer Cell. 2011;19(4):456-469. doi:10.1016/j.ccr.2011.03.009

33. Gao SP, Mark KG, Leslie K, et al. Mutations in the EGFR kinase domain mediate STAT3 activation via IL-6 production in human lung adenocarcinomas. $J$ Clin Invest. 2007;117(12):3846-3856. doi: $10.1172 / \mathrm{JCI} 31871$

34. Matsunaga T, Saito H, Murakami Y, et al. Serum level of C-reactive protein on postoperative day 3 is a predictive indicator of postoperative pancreatic fistula after laparoscopic gastrectomy for gastric cancer. Asian J Endosc Surg. 2017;10(4):382-387. doi:10.1111/ ases. 12374

35. Jung GH, Kim JH, Chung MS. Changes in weight, body composition, and physical activity among patients with breast cancer under adjuvant chemotherapy. Eur J Oncol Nurs. 2020;44:101680. doi:10.1016/ j.ejon.2019.101680

36. Prado CM, Antoun S, Sawyer MB, et al. Two faces of drug therapy in cancer: drug-related lean tissue loss and its adverse consequences to survival and toxicity. Curr Opin Clin Nutr Metab Care. 2011;14 (3):250-254. doi:10.1097/MCO.0b013e3283455d45

37. Argilés JM, Busquets S, Stemmler B, et al. Cancer cachexia: understanding the molecular basis. Nat Rev Cancer. 2014;14(11):754-762. doi: $10.1038 / \mathrm{nrc} 3829$

38. Walston JD, Matteini AM, Nievergelt C, et al. Inflammation and stress-related candidate genes, plasma interleukin-6 levels, and longevity in older adults. Exp Gerontol. 2009;44(5):350-355. doi:10.1016/j.exger.2009.02.004

39. Michaud M, Balardy L, Moulis G, et al. Proinflammatory cytokines, aging, and age-related diseases. J Am Med Dir Assoc. 2013;14 (12):877-882. doi:10.1016/j.jamda.2013.05.009

40. DEL GIUDICE M, Gangestad SW. Rethinking IL-6 and CRP: why they are more than inflammatory biomarkers, and why it matters. Brain Behav Immun. 2018;70:61-75. doi:10.1016/j.bbi.2018.02.013

41. Strassmann G, Fong M, Windsor S, et al. The role of interleukin-6 in lipopolysaccharide-induced weight loss, hypoglycemia and fibrinogen production, in vivo. Cytokine. 1993;5(4):285-290. doi:10.1016/ 1043-4666(93)90058-D

42. VAZQUEZ RODRIGUEZ G, Abrahamsson A, Jensen LD, et al. Estradiol promotes breast cancer cell migration via recruitment and activation of neutrophils. Cancer Immunol Res. 2017;5(3):234-247. doi:10.1158/2326-6066.CIR-16-0150

43. Diem S, Schmid S, Krapf M, et al. Neutrophil-to-Lymphocyte ratio (NLR) and Platelet-to-Lymphocyte ratio (PLR) as prognostic markers in patients with non-small cell lung cancer (NSCLC) treated with nivolumab. Lung Cancer. 2017;111:176-181. doi:10.1016/j. lungcan.2017.07.024

44. Zhang J, Zhang HY, Li J, et al. The elevated NLR, PLR and PLT may predict the prognosis of patients with colorectal cancer: a systematic review and meta-analysis. Oncotarget. 2017;8(40):68837-68846. doi:10.18632/oncotarget.18575

45. Iimori N, Kashiwagi S, Asano Y, et al. Clinical significance of the neutrophil-to-lymphocyte ratio in endocrine therapy for stage IV breast cancer. In Vivo (Brooklyn). 2018;32(3):669-675.

46. Yildiz Y, Kucukzeybek Y, Alacacioglu A, et al. Prognostic value of preoperative neutrophil-to-lymphocyte ratio and platelet-tolymphocyte ratio in patients with epithelial ovarian cancer. Eur J Gynaecol Oncol. 2017;38(3):444-448.

47. Fest J, Ruiter R, Mulder M, et al. The systemic immune-inflammation index is associated with an increased risk of incident cancer a population-based cohort study. Int $J$ Cancer. 2020;146 (3):692-698. doi:10.1002/ijc.32303
48. Deng C, Zhang N, Wang Y, et al. High systemic immune-inflammation index predicts poor prognosis in advanced lung adenocarcinoma patients treated with EGFR-TKIs. Medicine (Baltimore). 2019;98(33):e16875. doi:10.1097/MD.000000000 0016875

49. Jamieson T, Clarke M, Steele CW, et al. Inhibition of CXCR2 profoundly suppresses inflammation-driven and spontaneous tumorigenesis. J Clin Invest. 2012;122(9):3127-3144. doi:10.1172/ JCI61067

50. Deryugina EI, Zajac E, Juncker-jensen A, et al. Tissue-infiltrating neutrophils constitute the major in vivo source of angiogenesis-inducing MMP-9 in the tumor microenvironment. Neoplasia. 2014;16(10):771-788. doi:10.1016/j.neo.2014.08.013

51. Nozawa H, Chiu C, Hanahan D. Infiltrating neutrophils mediate the initial angiogenic switch in a mouse model of multistage carcinogenesis. Proc Natl Acad Sci U S A. 2006;103(33):12493-12498. doi:10.1073/ pnas.0601807103

52. Shojaei F, Singh M, Thompson JD, et al. Role of Bv8 in neutrophil-dependent angiogenesis in a transgenic model of cancer progression. Proc Natl Acad Sci U S A. 2008;105(7):2640-2645. doi:10.1073/pnas.0712185105

53. Welch DR, Schissel DJ, Howrey RP, et al. Tumor-elicited polymorphonuclear cells, in contrast to "normal" circulating polymorphonuclear cells, stimulate invasive and metastatic potentials of rat mammary adenocarcinoma cells. Proc Natl Acad Sci U S A. 1989;86(15):5859-5863. doi:10.1073/pnas.86.15.5859

54. Tiedt R, Schomber T, Hao-shen H, et al. Pf4-Cre transgenic mice allow the generation of lineage-restricted gene knockouts for studying megakaryocyte and platelet function in vivo. Blood. 2007;109 (4):1503-1506. doi:10.1182/blood-2006-04-020362

55. Glader P, Möller S, Lilja J, et al. Cigarette smoke extract modulates respiratory defence mechanisms through effects on T-cells and airway epithelial cells. Respir Med. 2006;100(5):818-827. doi:10.1016/j. rmed.2005.09.008

56. Kim S, Schein AJ, Nadel JA. E-cadherin promotes EGFR-mediated cell differentiation and MUC5AC mucin expression in cultured human airway epithelial cells. Am J Physiol Lung Cell Mol Physiol. 2005;289(6):L1049-1060. doi:10.1152/ajplung.00388.2004

57. Phillips J, Kluss B, Richter A, et al. Exposure of bronchial epithelial cells to whole cigarette smoke: assessment of cellular responses. Altern Lab Anim. 2005;33(3):239-248. doi:10.1177/026119290 503300310

58. Govindan R, Ding L, Griffith M, et al. Genomic landscape of non-small cell lung cancer in smokers and never-smokers. Cell. 2012;150(6):1121-1134. doi:10.1016/j.cell.2012.08.024

59. Chae YK, Davis AA, Agte S, et al. Clinical implications of circulating tumor DNA tumor mutational burden (ctDNA TMB) in non-small cell lung cancer. Oncologist. 2019;24(6):820-828. doi:10.1634/ theoncologist.2018-0433

60. Ravasco P, Monteiro-grillo I, MARQUES VIDAL P, et al. Impact of nutrition on outcome: a prospective randomized controlled trial in patients with head and neck cancer undergoing radiotherapy. Head Neck. 2005;27(8):659-668. doi:10.1002/hed.20221

61. Khalid U, Spiro A, Baldwin C, et al. Symptoms and weight loss in patients with gastrointestinal and lung cancer at presentation. Support Care Cancer. 2007;15(1):39-46. doi:10.1007/s00520-006-0091-0

62. Li XY, Yao S, He YT, et al. Inflammation-immunity-nutrition score: a novel prognostic score for patients with resectable colorectal cancer. J Inflamm Res. 2021;14:4577-4588. doi:10.2147/JIR. S 322260

63. Kim JH, Lee JH, Lee HS, et al. Elevated neutrophil-to-lymphocyte ratio in perioperative periods is suggestive of poor prognosis in patients with colorectal cancer. $J$ Inflamm Res. 2021;14:4457-4466. doi:10.2147/JIR.S327443 


\section{Publish your work in this journal}

The Journal of Inflammation Research is an international, peerreviewed open-access journal that welcomes laboratory and clinical findings on the molecular basis, cell biology and pharmacology of inflammation including original research, reviews, symposium reports, hypothesis formation and commentaries on: acute/chronic inflammation; mediators of inflammation; cellular processes; molecular mechanisms; pharmacology and novel anti-inflammatory drugs; clinical conditions involving inflammation. The manuscript management system is completely online and includes a very quick and fair peerreview system. Visit http://www.dovepress.com/testimonials.php to read real quotes from published authors. 